Historic, Archive Document

Do not assume content reflects current scientific knowledge, policies, or practices. 

62,17

From the

PECAN NURSERIES OF

E. E. STOKES \& SON, Campville, Fla.

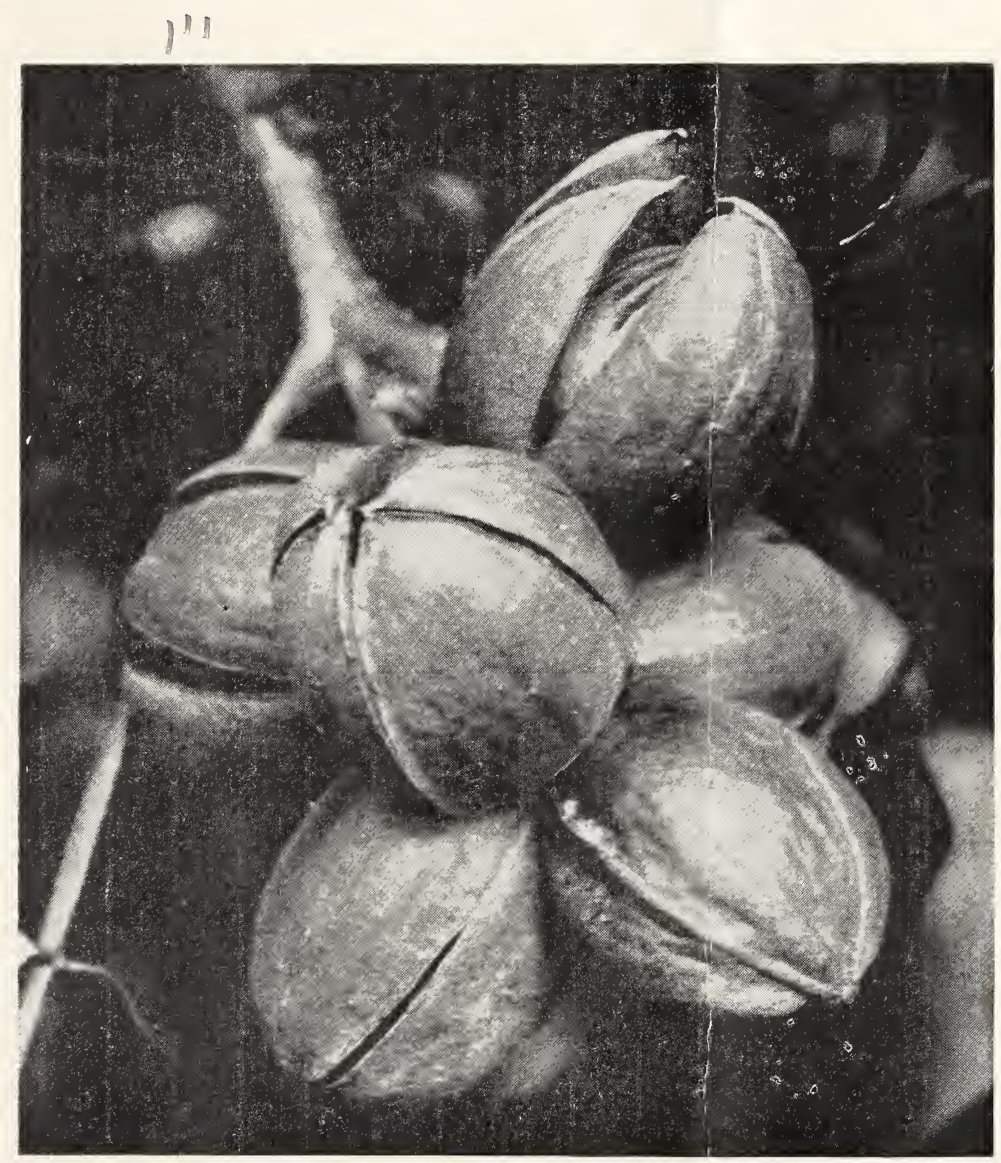

1925-1926

For 


\section{PECAN NURSERIES}

OF

\section{E. E. STOKES \& SON, Campville, Florida}

\section{MONEY IN PECANS}

The Pecan has now become thoroughly established as one of the highest grade nuts of commerce and there is a ready sale for it everywhere. The trees are very hardy and long lived and, with good care, bear great quantities of large nuts, rich meated and thin shelled.

The pecan nut has many fine qualities, such as imperishability (the nuts do not have to be sold at once when gathered, no matter how low the price, but can be kept for many months, if necessary), richness in fats and oils (the meat of the pecan is so rich in fats that it will burn like a candle when set afire), thin, easily cracked shell (in many varieties, the meat can be taken out whole with ease), and large size (forty or fifty of the nuts of some varieties will we: $g$ h a pound). The trees bear well over the South and many of the Middle States and, wherever they have once become established, more and more orchards are being set out all the time, as the demand for the nuts far exceeds the supply.

The trees we have for sale are fine, vigorous, stocky and well rooted and are grown from large, improved nuts of varieties most immune from scab and budded with budding wood from the finest and most prolific bearing trees in our orchards. We see to this personally, as indeed we do to all other phases of the work. Stock grown from large nuts grows faster and has many advantages over that grown from small pecans. Every orchardman should know this.

By many experiments during our twenty-two years of experience as nurserymen, we have found that the trees budded with buds from prolific trees, well into bearing, will bear quicker after setting out and also be much more prolific than those budded from buds from light bearers, or trees that have not yet come into bearing. Therefore, all our stock is budded only with buds from specially selected orchard trees. No one wishing to set out a pecan orchard can make a mistake if he uses these fine trees and gives them the proper care, as they are very hardy.

Our pecans have won six first prizes and two second prizes in eight entries in the Alachua County Fair.

We have orchard trees that bear from two to three hundred pounds of nuts each season and are still increasing their yields. Many of the young trees bear in the nurseries the first year. We have refused $\$ 1,000$ per acre for some of our ten and twelve year old groves. You cannot beat pecans for a paying investment. Thirty to fifty cents a pound is an average wholesale price here where they are grown and much better prices (up to a dollar a pound) can be secured by shipping out of the Pecan Belt.

Brooklyn, Florida.

I bought 800 budded pecan trees from E. E. Stokes \& Son. Although the following spring was dry I only lost $4 \frac{1}{2}$ percent. I was so well pleased with them that I afterward bought 4,600 and they have made a fine growth. Mr. Stokes is a splendid tree grower and I highly recommend him to those contemplating planting trees. 


\section{VARIETIES OF PECANS}

CURTIS. Originated by Dr. J. B. Curtis, Orange Heights, Fla., in 1886. This pecan has proven to be one of the most popular nuts grown. It is a great favorite on account of its prolific bearing, fast growing and fine quality. It is medium in size, very thin shelled, fine flavor, and the shell is always FULL of meat. The Curtis is a regular bearer and is one of the best commercial varieties on the market; in fact we sell more Curtis trees than all the other varieties combined that we grow.

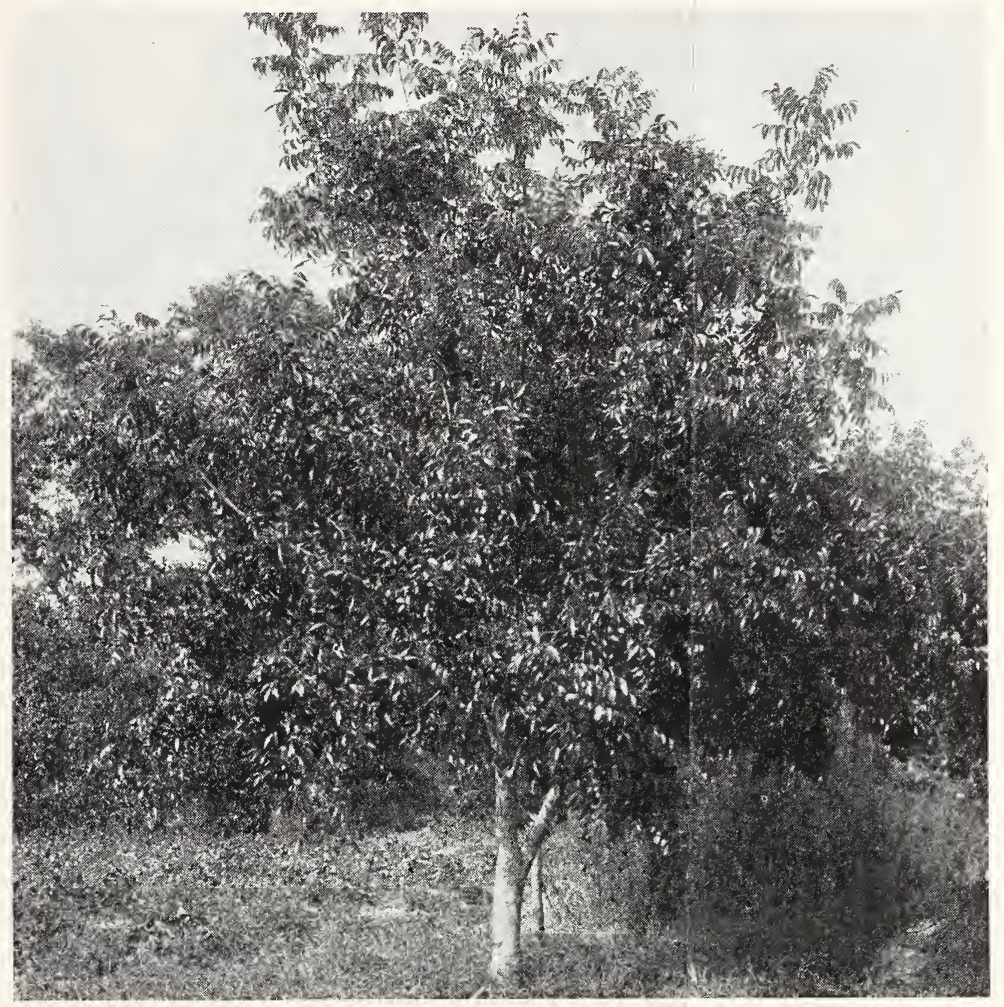

A PECAN TREE WELL INTO THE PROFITABLE STAGE

They become more valuable every year

MONEY MAKER. Very free from disease, one of the most prolific varieties we have; easy to crack out of shell whole, a very attractive and profitable nut and one that grows in favor annually.

PRESIDENT. The most prolific large nut we know of. Nut large sized, oblong, texture fine, fills well. Is widely known through pecan belt. Heavy bearer.

SUCCESS. Tree a good grower, heavy and regular bearer, nut large, oblong, tapering to apex, thin shell, large plump kernel, sweet flavor, a hig'. class variety and heavy bearer.

SCHLEY. Size above medium, oblong, oval, flattened; color, light reddish brown, marked with small specks about the base and small splashes of brown about the apex; base rounded, abruptly short; apex abrupt, flattened on two sides. This pecan is proving to be one of the most widely planted and popular nuts grown and we predict for it a great future. It is a large, fine nut, fairly prolific, fills well, a uniform bearer, and one of the most profitable and best selling varieties to plant.

STUART. Large to very large, about $17 \%$ by 1 inch; grayish brown, dotted with purplish black; base rounded; blunt both ends; 
shell medium thickness, cracking quality very good; kernel large, full, plump, solid, fine grained; flavor rich, sweet; quality good; a strong grower and a heavy bearer. Has proven adapted to a very wide range of country. One of the best.

PRICES ON BUDDED AND GRAFTED PECAN TREES

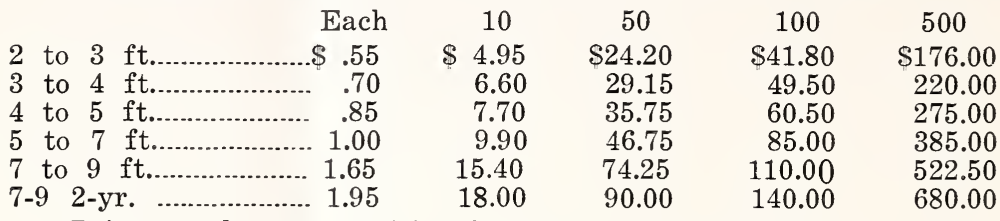

Prices on large quantities furnished on application.

Plant pecan trees $60 \mathrm{ft}$. each way, 12 trees to the acre. Use square system.

Keystone Heights, Fla.

Dec. 14, 1925.

Mr. C. M. Stokes,

Green Cove Springs, Fla.

Dear Mr. Stokes:

I understand you will plant a number of pecan trees this winter and wish to say after several years planting and twenty four hundred acres set out with trees from different nurseries, that I had the smallest loss and the best growth from the nurseries of E. E. Stokes \& Son of Campville, Florida, and in the past three years I have planted nothing but trees from the Stokes Nurseries.

I had a loss of many thousand dollars on pecan trees which would have been avoided had I bought all my trees from Mr. Stokes.

I know his trees to be superior in many ways to those from many nurseries. I am interested in the pecan industry and that is the reason I write you.

Yours truly,

J. J. LAWRENCE.

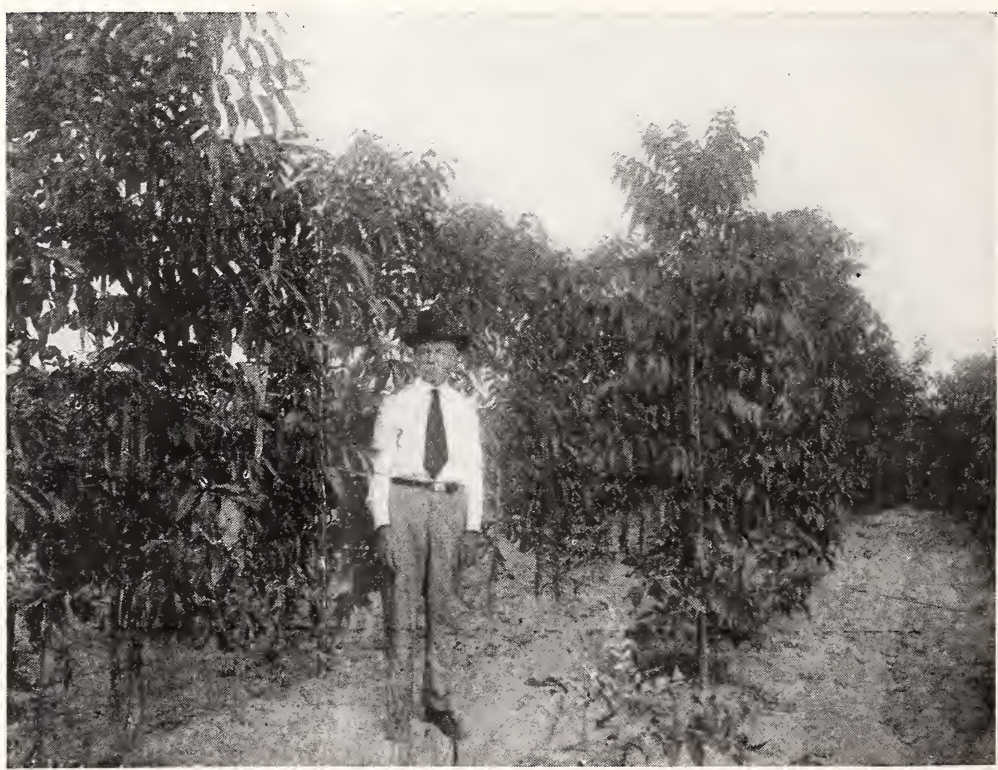

E. E. STOKES IN HIS BUDDED PECAN NURSERY

Note the height and sturdy character of the stock 


\section{ORANGES}

CHINESE HONEY. Brought here by a missionary from China. A Kid Glove orange of high quality; the sweetest we have ever eaten. It makes good growth. Will stand almost as much cold as the Satsuma.

PRICE OF CHINESE HONEY ORANGE TREES

\begin{tabular}{|c|c|c|c|c|}
\hline & Each & 10 & 50 & 100 \\
\hline 2 to $3 \mathrm{ft}$ & $\$ 2.00$ & $\$ 18.50$ & $\$ 87.50$ & $\$ 165.00$ \\
\hline 3 to 4 & .. 2.25 & 20.00 & 75.00 & 175.00 \\
\hline 4 to 7 & 2.50 & 25.00 & 100.00 & 190.00 \\
\hline
\end{tabular}

Prices for large quantities furnished on application.

PARSON BROWN. Fruit is medium to large size, quality good, ready for market in November or earlier. Fine market variety.

PINEAPPLE. Fruit of good size, of a deep rich red and fully developed. Quality unsurpassed with a flavor resembling the pineapple in taste and odor. Trees bear well and fruit ripens in January and February.

DANCY TANGERINE. Is best known of the "Kid Glove" varieties. Trees are heavy bearers and good money makers.

SATSUMA. Very hardy; can be grown over Lower South without danger from cold. Skin, "kid glove" type, easily removed with fingers; ripens in October and early November; quality excellent. We grow the popular Owari strain.

\section{PRICES ON SATSUMAS}

\begin{tabular}{|c|c|c|c|}
\hline Sizes & Each & 10 & 100 \\
\hline to $3 \mathrm{ft}$ & $\$ .50$ & $\$ 4.50$ & $\$ 40.00$ \\
\hline to $4 \mathrm{ft}$ & .70 & 6.00 & 55.00 \\
\hline 4 to $5 \mathrm{ft}$ & .90 & 8.00 & 75.00 \\
\hline to $7 \mathrm{ft}$ & 1.10 & 10.00 & 90.00 \\
\hline to $9 \mathrm{ft}$ & 1.50 & 13.00 & 115.00 \\
\hline
\end{tabular}

Mr. E. E. Stokes,

Lake Geneva, Clay Co., Florida.

Pecan Nursery, Campville, Florida.

Dear Mr. Stokes:

It has occurred to me that I might be of benefit to you, and to those contemplating the purchase of budded paper shell pecan stock as well, in stating briefly my experience with your trees.

I purchased sufficient stock from you to plant fifteen acres of surface here for Mr. H. Edwards, his land being situated in about the center of our development a short distance out from Lake Geneva. The formation is similar to the balance of our tract-high pine land underlaid with red clay.

These trees arrived in splendid condition and were all planted immediately. Every tree lived and put out a fine growth the following spring. Five acres more have been added since and this twentyacre young grove is a sight good to look upon.

I have since purchased from you enough trees for twenty-five acres more, twenty acres being for Mr. R. T. Weir and five for myself. They are just like the first, perfect in every way and exceptionally fine.

We planted them carefully and this spring every one of them lived and made a splendid growth this season.

I cannot recommend your stock too highly, having had experience also with other nurseries, and would advise all planters of budded paper shell pecans to use your trees exclusively if it were possible to obtain them.

Very truly yours,

R. C. JENKINS,

Associated Pecan Growers, Lake Geneva, Fla. 
PRICES OF ORANGE TREES ON LARGE SOUR STOCK

\begin{tabular}{lrrrrr} 
& Each & 10 & 100 & \multicolumn{1}{c}{500} & \multicolumn{1}{c}{1000} \\
2 to 3 ft.................... .65 & $\$ 6.00$ & $\$ 55.00$ & $\$ 265.00$ & $\$ 500.00$ \\
3 to 4 ft................ .90 & 8.00 & 75.00 & 360.00 & 700.00 \\
Large, heavy tops.. 1.75 & 16.50 & 150.00 & 700.00 & 1350.00 \\
3 yr. old buds........ 2.00 & 17.50 & 160.00 & 750.00 & 1450.00
\end{tabular}

Plant round oranges $30 \mathrm{ft}$. each way.

We also handle peach and other kinds of fruit trees adapted to this climate. Our long experience in growing fruit trees in this state enables us to select for our customers such as will give them the best service.

\section{TERMS OF BUSINESS}

Shipping season from November to March first.

We substitute when not otherwise instructed.

Terms cash.

If an error should occur and same be reported to us, promptly, we will correct same or refund purchase price.

When trees are delivered to transportation company in good order, our responsibility ceases.

Trees baled or boxed carefully.

Come and see our nurseries and groves, showing what can be done when good trees are planted.

In planting trees, dig hole large and roomy. Do not set trees below earthen collar mark. If soil is wet and heavy, plant 1 to 2 inches above collar mark; keep roots straightened out naturally, put in top soil. When tree is two-thirds planted, put in 1 to 2 buckets of water. Pack soil firm, mulch.

Write us about your soils. Our advice, based on long experience is yours for the asking.

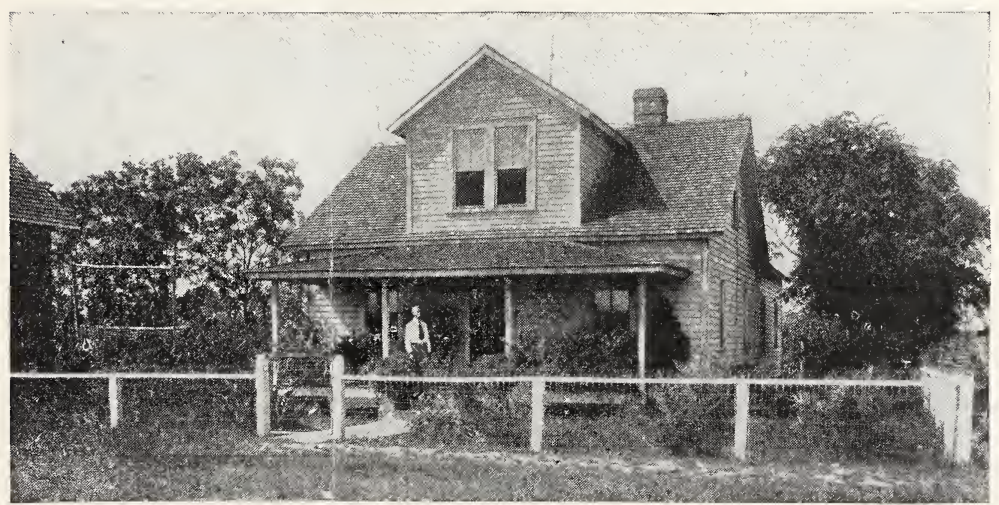

RESIDENCE OF E. E. STOKES, CAMPVILLE, FLA.

For twenty-two years E. E. Stokes has devoted his time to the propagation of nursery stock, specializing in pecans. The result of this ripe experience is yours when you buy Stokes Pecan Trees. 